\title{
Composição química da silagem de gliricídia submetida a diferentes consorciações de
}

\section{ensilagens}

\author{
Chemical composition of gliricidia silage subjected to different ensilion soots \\ Composición química del ensilado gliricidia sometido a diferentes hollínes de ensilión
}

Recebido: 27/06/2021 | Revisado: 04/07/2021 | Aceito: 08/07/2021 | Publicado: 17/07/2021

Haroldo Wilson da Silva
ORCID: https://orcid.org/0000-0003-2360-8599
Universidade Estadual Paulista “Júlio de Mesquita Filho", Brasil
E-mail: haroldowsilva@gmail.com
Sidinei Favarin
ORCID: https://orcid.org/0000-0001-9782-4265
Faculdade de Tecnologia de São Paulo, Brasil
E-mail: sidnei.favarin@ @atec.sp.gov.br
Arleto Tenório dos Santos
ORCID: https://orcid.org/0000-0002-0353-3609
Escola Prof. Dr. Antônio Eufrásio de Toledo, Brasil
E-mail: arletotenorio@ @ahoo.com.br
Eudes Barros de Araújo
ORCID: https://orcid.org/0000-0001-7305-0656
Faculdade de Tecnologia de São Paulo, Brasil
E-mail: eaeudes2@gmail.com
Angela Madalena Marchizelli Godinho
ORCID: https://orcid.org/0000-0001-5376-6681
Faculdade de Tecnologia de São Paulo, Brasil
E-mail: angela.godinho@ @atec.sp.gov.br

\section{Resumo}

Objetivou-se avaliar as características químicas da silagem de gliricídia em função de diferentes consorciações de ensilagens. O primeiro corte das plantas foi feito um ano após o plantio, à altura de $50 \mathrm{~cm}$ da superfície do solo. As silagens foram distribuídas em um delineamento experimental inteiramente casualizado com quatro unidades por tratamento (microsilos) com quatro repetições. Optou-se por período de fermentação da ensilagem de sessenta dias. Os tratamentos consistiram em cinco diferentes processos de ensilagem, sendo eles: T1 - gliricídia consorciada com sorgo (30\%, 40\% e 50\% do peso da matéria verde); $\mathrm{T} 2$ - gliricídia consorciada com polpa cítrica (30\%, $40 \%$ e 50\% do peso da matéria verde); T3 - gliricídia emurchecida em estufa considerando (uma, duas e três horas); T4 - gliricídia in natura e T5 - gliricídia consorciada com milho moído (30\%, 40\% e 50\% do peso da matéria verde). Conclui-se que a gliricídia demonstrou que é uma leguminosa que altera suas características químicas de acordo com a consorciação utilizada durante o processo de ensilagem.

Palavras-chave: Conservação de forragem; Leguminosa arbórea; Produção vegetal.

\begin{abstract}
The objective of this study was to evaluate the chemical characteristics of gliricidia silage as a function of different ensilion sorrities. The first cut of the plants was made one year after planting, at the height of $50 \mathrm{~cm}$ from the soil surface. The silages were distributed in a completely randomized experimental design with four units per treatment (microsilos) with four repetitions. It was decided by fermentation period of the silage of sixty days. The treatments consisted of five different silage processes: T1 - gliricidia consorcised with sorlum $(30 \%, 40 \%$ and $50 \%$ of the weight of green matter); T2 - gliricidia conorted with citrus pulp (30\%, $40 \%$ and $50 \%$ of the weight of green matter); T3 gliricidia enurchecidal in greenhouse considering (two, three and four hours); T4 - gliricidia in natura and T5 - gliricidia concrophernated with ground corn $(30 \%, 40 \%$ and $50 \%$ of the weight of green matter). It was concluded that gliricidia demonstrated that it is a legume that alters its chemical characteristics according to the consorciation used during the silage process.
\end{abstract}

Keywords: Forage conservation; Tree leguminosa; Vegetable production.

\section{Resume}

El objetivo de este estudio fue evaluar las características químicas del ensilado gliricidia em función de diferentes hermandades de ensilión. El primer corte de las plantas se realizó un año después de la siembra, a la altura de $50 \mathrm{~cm}$ de la superficie del suelo. Los silages se distribuyeron en un diseño experimental completamente aleatorizado con cuatro unidades por tratamiento (microsilos) con cuatro repeticiones. Se decidió por período de fermentación del ensilado de sesenta días. Los tratamientos consistieron en cinco procesos de ensilado diferentes: $\mathrm{T} 1$ - gliricidia consorcizada con 
sorlum $(30 \%, 40 \%$ y $50 \%$ del peso de la materia verde); T2 - gliricidia conordida con pulpa de cítricos $(30 \%, 40 \%$ y $50 \%$ del peso de la materia verde); T3 - gliricidia enurchecidal en invernadero considerando (dos, tres y tres horas); T4 - gliricidia in natura y T5 - gliricidia concrofernated con maíz molido (30\%, $40 \%$ y $50 \%$ del peso de materia verde). Se concluyó que gliricidia demostró que es una leguminosa que altera sus características químicas según la consorciación utilizada durante el proceso de ensilado.

Palabras clave: Conservación de forrajes; Árbol leguminosa; Producción de hortalizas.

\section{Introdução}

A utilização de forrageiras leguminosas passa a ser uma alternativa para a redução de custos, por apresentarem elevado teor de proteína digestível, elevada produção de biomassa.

Uma vez que, a alimentação tem grande impacto no custo de produção animal sendo o milho e farelo de soja os ingredientes presentes em maior proporção na ração concentrada. $\mathrm{O}$ uso de forragens alternativas, de fácil cultivo e baixo custo podem contribuir significativamente para substituir os alimentos tradicionalmente utilizados e ainda suprir a necessidade de alimento para o rebanho.

Aliado a este fato, entre as leguminosas arbóreas a gliricídia é uma espécie forrageira que desperta interesse para alimentação animal principalmente quando se considera seu elevado teor proteico em torno de $24 \%$ de proteína bruta e sua elevada produção de massa foliar. Neste âmbito, quando se considera seu alto teor proteico dar-se escolha pela gliricídia, pois proporciona o atendimento às exigências nutricionais em proteína.

Existem vários estudos que avaliam o uso da gliricídia para alimentação de ruminantes. Entretanto, há que se considerar que existe na literatura variada opinião sobre a composição químico-bromatológica e poucos relatos relacionado a intensidade, frequência, idade de corte para condições edafoclimáticas no Brasil.

As leguminosas forrageiras apresentam forte apelo ambiental, devido a capacidade de fixação de nitrogênio no solo, que pode contribuir como fonte alternativa à ureia para provisão de nitrogênio e fonte de suplementação proteica em contraposição a ureia e ao uso do farelo de soja na alimentação animal.

Cabe, aqui destacar que essa leguminosa tem mostrado muitas vantagens de cultivo para alimentação de ruminantes, como alta retenção foliar, principalmente de folhas jovens, e uma boa capacidade de rebrota após o corte. Em outras palavras a capacidade de recuperação, após o corte, é uma característica importante em forrageiras destinadas a bancos de proteína.

Neste contexto, buscou-se a partir dessa pesquisa saber: A consorciação da ensilagem com sorgo, polpa cítrica, milho moído e a técnica do emurchecimento propicia qualidade à silagem de gliricídia?

Sendo assim, objetivou-se avaliar as características químicas da silagem de gliricídia em função de diferentes consorciações de ensilagens.

\section{Material e Métodos}

O experimento foi conduzido no setor experimental na Faculdade de Tecnologia de São Paulo nas dependências da FATEC de Presidente Prudente, localizada no extremo oeste do estado de São Paulo, situada nas coordenadas geográficas com latitude $22^{\circ} 07^{\prime} 04^{\prime \prime} \mathrm{S}$ e longitude $51^{\circ} 22^{\prime} 57^{\prime \prime} \mathrm{W}$, com altitude de 472 metros acima do nível do mar e temperatura entre $15^{\circ} \mathrm{C}$ a 32 oC, com média de $21,6^{\circ} \mathrm{C}$ e uma pluviosidade média anual de $1207 \mathrm{~mm}$.

A área experimental foi implantada por produção de mudas por sementes em covas no dia 30 de abril de 2019 , no espaçamento de $1,0 \mathrm{~m}$ entre linhas e $0,5 \mathrm{~m}$ entre plantas, referente à população de 20.000 plantas ha ${ }^{-1}$. $\mathrm{O}$ corte das plantas foi realizado a $0,50 \mathrm{~m}$ de altura em relação ao solo com a utilização de foices. Optou-se por realizar o primeiro corte aos 12 meses para ensilagem de gliricídia consorciada. 
$\mathrm{O}$ solo da área experimental apresentou os seguintes atributos químicos (perfil de 0 a $20 \mathrm{~cm}$ ): $\mathrm{pH}\left(\mathrm{CaCl}_{2}\right)$ : 6,7; matéria orgânica: $16\left(\mathrm{~g} \mathrm{dm}^{-3}\right) ; \mathrm{P}_{(\text {resina) }}: 402\left(\mathrm{mg} \mathrm{dm}^{-3}\right) ; \mathrm{Al}^{3+}: 0 ; \mathrm{H}+\mathrm{Al}: 14\left(\mathrm{mmol}_{\mathrm{c}} \mathrm{dm}^{-3}\right) ; \mathrm{K}: 3,1\left(\mathrm{mmol}_{\mathrm{c}} \mathrm{dm}^{-3}\right) ; \mathrm{Ca}: 235\left(\mathrm{mmol}_{\mathrm{c}} \mathrm{dm}^{-3}\right) ; \mathrm{Mg}: 73$ $\left(\mathrm{mmol}_{\mathrm{c}} \mathrm{dm}^{-3}\right)$; saturação de bases: 311 e CTC: 325 . Procedeu-se o cultivo sem considerar realizar correção do solo, no entanto, efetuou-se a adubação de cobertura com superfosfato simples $\left(18 \%\right.$ de $\left.\mathrm{P}_{2} \mathrm{O}_{5}\right)$ na proporção de $500 \mathrm{~kg}$ por ha ${ }^{-1}$.

Quanto a metodologia é uma pesquisa de campo qualitativa descritiva. As silagens foram distribuídas em um delineamento experimental inteiramente casualizado com quatro unidades por tratamento (microsilos) com quatro repetições. Optou-se por período de fermentação da ensilagem de sessenta dias. Os tratamentos consistiram em cinco diferentes processos de ensilagem, sendo eles: T1 - gliricídia consorciada com sorgo (30\%, 40\% e 50\% do peso da matéria verde); T2 - gliricídia consorciada com polpa cítrica (30\%, 40\% e 50\% do peso da matéria verde); T3 - gliricídia emurchecida em estufa considerando (duas, três e quatro horas); T4 - gliricídia in natura e T5 - gliricídia consorciada com milho moído (30\%, 40\% e 50\% do peso da matéria verde).

As análises químico-bromatológica foram realizadas no Laboratório de Bromatologia da Faculdade de Ciências Agrárias pertencente a Universidade do Oeste Paulista - UNOESTE, sobre os níveis de matéria seca (MS), proteína bruta (PB). extrato etéreo (EE), fibra em detergente ácido (FDA) e fibra em detergente neutro (FDN) e nutrientes digestíveis totais (NDT).

\section{Resultados e Discussão}

A produção de biomassa verde da gliricídia foi satisfatória atingiu 61.169,33 com corte realizado após os doze meses de plantio. De acordo com Murgueitio et al. (1999) o início do corte é feito quando a planta alcança 1,5 m de altura. Enquanto para Cook et al. (2005) para produção de forragem é recomendado primeiro corte com 8-12 meses após a semeadura a altura de 0,5-1,0 m e, posteriormente, de 2 a 4 meses dependendo da temperatura e precipitação.

Os resultados da análise química de gliricídia in natura, sorgo e polpa cítrica são apresentados em relação ao parâmetro de valores de Matéria Seca (MS), Proteína Bruta (PB), Fibra Bruta (FB), Fibra em Detergente Neutro (FDN), Fibra em Detergente Ácido (FDA) e Nutrientes Digestíveis Totais (NDT) obtiveram respectivamente valores descritos na (Tabela 1).

Tabela 1. Composição químico-bromatológica de gliricídia, sorgo e polpa cítrica in natura.

\begin{tabular}{lccc}
\hline Parâmetros & Gliricídia & Sorgo & Polpa cítrica \\
\hline Matéria seca & 21,91 & 24,44 & 87,35 \\
Proteína bruta & 21,26 & 14,03 & 11,64 \\
Extrato Etéreo & 2,73 & 1,15 & 2,53 \\
Fibra em detergente ácido & 26,78 & 40,51 & 28,72 \\
Fibra e detergente neutro & 51,96 & 70,54 & 26,86 \\
Nutrientes totais digestíveis & 68,04 & 57,34 & 66,52 \\
\hline
\end{tabular}

Fonte: Autores (2020).

O valor da matéria seca aqui apresentado para gliricídia in natura ficou abaixo do preconizado para o preparo de silagem de boa qualidade. Por outro lado, o valor de proteína bruta 21,26. Segundo Carvalho Filho et al. (1997), a espécie apresenta em sua composição bromatológica medias de 20,7\% de proteína bruta. De acordo Kass (1993) a composição química de G. sepium varia segundo a idade, parte da planta, procedência e local de plantio. Além disso, Mertens (1994) relatou que o valor nutritivo das forragens varia entre partes das plantas. Segundo Carvalho Filho et al. (1997), a espécie apresenta em sua composição bromatológica medias de $20,7 \%$ de proteína bruta. 
Entretanto, o teor de proteína bruta semelhante ao teor de proteína bruta e maior numericamente ao teor de matéria seca encontrados por Matos et al. (2005) em relação do efeito da idade da planta sobre o conteúdo de proteína bruta (PB) planta jovem $(21,2)$ e matéria seca (MS) planta jovem $(19,6)$. Por sua vez foi inferior numericamente abaixo dos valores encontrados por Juma et al. (2006) que avaliando forragens de gliricídia reportaram valores de MS 25,0, PB 23,2, FDN 50,6, FDA 30,3.

Em experimento realizado por Costa et al. (2009) para avaliar folhas frescas de Gliricidia sepium por ovinos, os resultados da análise química da gliricídia in natura mostraram que as folhas apresentaram valores em quantidade que difere numericamente nos dois tratamentos dessa pesquisa nos parâmetros de Proteína bruta $(24,11)$ e Matéria seca $(23,11)$.

Enquanto, Andrade e Lima (2013) realizaram estudo sobre a produção de massa forrageira e a qualidade nutricional da gliricídia encontraram teor de PB (26,87\%), no qual é superior a todos os valores citados nessa pesquisa. A este respeito, Edvan et al., (2013), avaliando a composição bromatológica da gliricídia in natura com objetivo para ensilagem encontraram valor semelhante ao teor de PB $(25,85)$. Este conhecimento se torna ainda mais importante quando se trata da avaliação de uma forrageira para inclusão na dieta como fonte de proteína.

É importante salientar que os níveis de MS da forragem in natura de sorgo estão abaixo do recomendado para produção de silagem, que segundo McDonald (1981) o teor de matéria seca da forragem deve estar entre 30,0 e 35,0\%, para que o processo fermentativo ocorra de forma satisfatória.

Em relação as silagens de gliricídia os resultados da análise química de gliricídia in natura, sorgo e polpa cítrica são apresentados em relação ao parâmetro de valores de Matéria Seca (MS), Proteína Bruta (PB), Fibra Bruta (FB), Fibra em Detergente Neutro (FDN), Fibra em Detergente Ácido (FDA) e Nutrientes Digestíveis Totais (NDT) obtiveram respectivamente valores descritos na (Tabela 2).

Tabela 2. Composição químico-bromatológica de silagem de gliricídia in natura consorciada com sorgo forrageiro, polpa cítrica, emurchecida e milho moído.

\begin{tabular}{lcccccc}
\hline Parâmetros & MS & EE & PB & FDN & FDA & NDT \\
\hline & & & & & & \\
Silagem gliricídia in natura & 19,85 & 3,38 & 22,13 & 55,41 & 25,27 & 69,21 \\
Silagem gliricídia + 30\% sorgo & 20,79 & 3,25 & 20,09 & 36,36 & 25,56 & 68,99 \\
Silagem gliricídia + 40\% sorgo & 22,58 & 2,84 & 16,82 & 40,08 & 29,05 & 66,27 \\
Silagem gliricídia + 50\% sorgo & 22,10 & 2,37 & 17,77 & 42,72 & 28,92 & 66,27 \\
Silagem gliricídia + 30\% polpa cítrica & 33,09 & 4,18 & 15,90 & 31,31 & 27,30 & 67,64 \\
Silagem gliricídia + 40\% polpa cítrica & 39,82 & 3,83 & 13,75 & 29,74 & 26,22 & 68,48 \\
Silagem gliricídia + 50\% polpa cítrica & 41,20 & 8,05 & 12,98 & 27,96 & 27,46 & 67,51 \\
Silagem gliricídia emurchecida 2h & 25,72 & 3,18 & 20,51 & 51,12 & 21,51 & 75,15 \\
Silagem gliricídia emurchecida 3h & 30,05 & 2,92 & 20,51 & 62,56 & 29,88 & 65,63 \\
Silagem gliricídia emurchecida 4h & 45,40 & 3,12 & 20,51 & 60,50 & 23,88 & 70,30 \\
Silagem gliricídia + 30\% milho & 38,23 & 5,31 & 13,87 & 56,79 & 9,63 & 81,40 \\
Silagem gliricídia + 40\% milho & 43,57 & 5,41 & 13,23 & 60,01 & 6,90 & 83,53 \\
Silagem gliricídia + 50\% milho & 53,59 & 5,17 & 12,03 & 58,40 & 5,65 & 84,50 \\
\hline
\end{tabular}

MS = Matéria Seca; $\mathrm{PB}=$ proteína bruta; $\mathrm{EE}$ = Extrato Etéreo; FDN = fibra em detergente neutro; FDA = fibra em detergente ácido; NDT = Nutrientes Digestivos Totais.

Fonte: Autores (2020). 
A matéria seca do componente gliricídia in natura encontra-se abaixo dos valores toleráveis propostos por Cruz et al., (2000), para preparo de silagens, que é de 30 a 40\%. Carvalho Filho et al. (1997), mensuram teor de proteína bruta da silagem de gliricídia em PB: 23,04. Enquanto, Drumond e Carvalho Filho (1999) realizaram análise bromatológica de silagem exclusiva de gliricídia encontraram valores numericamente maior para matéria seca (MS 36,29) e menor para proteína bruta (PB 19,18). Por sua vez, Drumond \& Morgado (2004) realizaram análise bromatológica de gliricídia com base na matéria seca encontraram valores de matéria seca (MS: 30,97) e proteína bruta (PB: 22,82).

Trabalhos como o de Dantas et al. (2008) e Silva et al. (2015) comprovam o bom valor nutricional da silagem de gliricídia. Entretanto, assim como as demais leguminosas, a gliricídia apresenta algumas limitações para o processo de ensilagem, como o alto poder tampão, o baixo teor de carboidratos solúveis e baixo teor de matéria seca (LEONEL et al., 2008). Com isso, a inclusão de alguns materiais no momento da ensilagem pode corrigir algumas dessas características indesejáveis.

Em outro estudo realizado por Souza et al. (2012) para avaliar a qualidade das silagens de gliricídia inteira (GI) ou moída (GM), encontraram valores médios de matéria seca (MS) 22,3 e 24,4; proteína bruta (PB) 20,04 e 20,2; fibra em detergente neutro (FDN) 37,6 e 39,0; fibra em detergente ácido (FDA) 31,7 e 31,2; estrato etéreo (EE) 3,7 e 3,3 respectivamente.

Campos et al. (2017) avaliaram a influência de dietas com silagens de plantas forrageiras adaptadas às condições semiáridas na alimentação de cordeiros e, dentre estas silagens, estava a gliricídia, com valores de 42,2\% de MS; 38,8\% de MO; 5,5\% de PB; 0,9\% de EE; 10,0\% de FDNcp; 20,4\% CNF e 30,3\% NDT. Assim, foi relatado ganho de peso de $190 \mathrm{~g} \mathrm{dia}^{-1}$, demonstrando que apesar das características desfavoráveis para o processo de ensilagem, os ovinos apresentaram desempenho elevado ao utilizar uma dieta com 50\% de silagem de gliricídia e 50\% de farelo de milho.

A silagem emurchecida proporcionou melhor teor de matéria seca em relação as silagens de in natura, sorgo e polpa cítrica. A realização de um pré-tratamento, como emurchecimento ou o uso de aditivos podem melhorar algumas características do material ensilado e assim promover uma melhor fermentação (ITAVO et al., 2010).

Por sua vez, apesar do emurchecimento favorecer as características do material a ser ensilado, elevados tempos de emurchecimento podem acarretar consumo de carboidratos solúveis da forragem durante o processo de respiração, ocasionando redução da degradabilidade dos nutrientes, devido a alterações nos componentes fibrosos, diminuindo a qualidade do material e aumentando o número de fungos e leveduras no material a ser ensilado (SANTOS et al., 2010).

Entretanto as silagens de milho proporcionaram alto teor de matéria e redução no teor de proteína bruta. Estudo realizado por Costa et al. (2007) com a silagem de gliricídia em substituição parcial da silagem de milho por silagem de gliricídia na ordem de $20 \%$ e $40 \%$ da matéria seca. Os autores concluíram que tratamento com substituição da ordem de $40 \%$ de gliricídia em relação à silagem de milho mostrou-se superior.

\section{Conclusões}

Conclui-se que a gliricídia demonstrou que é uma leguminosa que altera suas características químicas de acordo com a consorciação utilizada durante o processo de ensilagem. Os parâmetros químicos da silagem de gliricídia in natura e consorciada com sorgo obtiveram os menores teores de matéria seca, enquanto a consorciação com polpa cítrica e milho proporcionou o menor teor de proteína bruta. Por sua vez a técnica de emurchecimento antes das ensilagens da gliricídia com (2h, 3h e 4h) proporcionaram aumento no teor de matéria seca e numericamente não deferiu no teor de proteína bruta em relação a gliricídia in natura, o que torna a técnica de emurchecimento recomendada para ensilagem de gliricídia. Contudo é preciso a pesquisa seja replicada em outro estudo. 


\section{Referências}

Andrade, R. R. \& Lima, N. R. S. (2013). Análise da qualidade fisiológica e sanitária das sementes de gliricídia (Gliricidia sepium (Jacq.) Steud.). Cadernos de Graduação - Ciências Biológicas e da Saúde, 1, 135-146

Campos, F. S., Carvalho, G. G. P., Santos, E. M. Araújo, G. G. L. Gois, G. C. \& Rebouças, R. A. (2017). Influence of diets with silage from plants adapted to semi-arid conditions on lamb quality and sensory atributes. Meat Science. 124, 61-68.

Carvalho Filho, O. M. de, Drumond, M. A., \& Languidey, P. H. (1997). Gliricidia sepium, leguminosa promissora para regiões semiáridas. Petrolina: EMBRAPA-CPATSA, (Circular Técnica, 35).

Cook, B. G., Pengelly, B. C., Brown, S. D., Donnelly, J. L., Eagles, D. A., \& Franco, M. A. Tropical Forages: an interactive selection tool. Brisbane: CSIRO, DPI\&F(Qld), CIAT and ILRI, 2005.

Cruz, J. C., Ferreira, J. J., Viana, A. C., \& Pereira Filho, I. A. (2000). Avaliação de cultivares de milho para a produção de Silagem. In: Congresso Nacional de Milho e Sorgo, 23., Uberlândia. Anais ... Sete Lagoas.

Carvalho, C. B. M. de, Silva, S. F., Carneiro, M. S. de, Edvan R. L., \& Pereira, E. S. (2013). Perdas e composição bromatológica de silagem de gliricídia contendo diferentes níveis de vargem de algaroba. Revista Tecnologia e Ciência Agropecuária, 7, 63-68.

Costa, B. M. da, A, I.C.V. Santos, A. I. C.V., Oliveira, G. J. C. de, \& Pereira, I. G. Avaliação de Folhas de Gliricídia sepium (Jacq.) Walp Por Ovinos. (2009). Revista Archivos de Zootecnia, 58 (221): 33-41.

Costa, C. X., Muniz, E. N., SA, C. O. de, SA, J. L. de, Rangel, J. H. de \& Farias, I. L. de. (2007). Efeito da substituição parcial da silagem de milho por silagem de gliricídia sobre o desenvolvimento de cordeiras Santa Inês alimentadas em confinamento. In: Anais do III Simpósio Internacional sobre Caprinos e Ovinos de Corte, João Pessoa, Paraíba, Brasil, 05 a 10 de novembro.

Dantas, A. F., Pereira Filho, J. M., Silva, A. M. A., Santos, E. M., Souza, B. B. \& Cézar, M. F. (2008). Características da carcaça de ovinos Santa Inês terminados em pastejo e submetidos a diferentes níveis de suplementação. Ciência e Agrotecnologia, 32, .1280.

Drumond, M. A. \& Morgado, L. B. (2004). Espécies arbóreas alternativas para sistemas agroflorestais no semiárido brasileiro. Agrossilvicultura, 1, 43-50

Drumond, M. A. \& Carvalho Filho, O. M. de. (1999). Introdução e avaliação da Gliricidia sepium na região semiárida do Nordeste brasileiro. In: Queiroz, M. A. de; Goedert, C. O.; Ramos, S. R. R. (Ed.). Recursos genéticos e melhoramento de plantas para o Nordeste brasileiro. Petrolina: Embrapa Semiárido; Brasília, DF: Embrapa Recursos Genéticos e Biotecnologia.

Juma, H. K.; Abdulrazak, S. A.; Muinga, R. W. \& Ambula, M. K. (2006). Effects of supplementing maize stover witch clitoria, gliricídia and mucuna on performance of lactating Jersey cows in coastal lowland Kenya. Tropical and Subtropical Agroecosystens, 6,1 - 7.

Leonel, F. P. de, Pereira, J. C., Marcone, G. C., Marco Júnior, P. de, Lara, L. A. Sousa, D. P.de, \& Silva, C. J. da. (2008). Consórcio capim-braquiária e soja, produtividade das culturas e características qualitativas das silagens. Revista Brasileira de Zootecnia, 37, 2031-2040.

Matos, L.V., Campello, E. F. C., \& Resende, A. S. de. (2005). Plantio de Leguminosas Arbóreas para Produção de Moirões Vivos e Construção de Cercas Ecológicas. Embrapa Agrobiologia, 105.

Mcdonald, P. The biochemistry of silage. John Willey \& Sons.1981. 226p.

Mertens, D. R. (1994). Regulation of forage intake. In: Fahey Jr., G. C., Collins, M., Mertens, D. R et al. (Eds). Forage quality evaluation and utilization. Nebraska: American Society of Agronomy, Crop Science of America, Soil Science of America, 450-493.

Murgueitio, E., Rosales, M., \& Gómez, M. E. (1999). Agroforestería para la producción animal sostenible. Centro para la investigación en sistemas sostenibles de producción agropecuaria CIPAV. Cali, Colombia, $67 \mathrm{p}$.

Santos, M.V.F, Gómez Castro, A. G., Perea, J. M., García A., Guim A. \& Pérez Hernández M. (2010). Fatores que afetam o valor nutritivo das silagens de forrageiras tropicais. Archivos de Zootecnia, 59 (R): 25-43.

Silva, M. D. A., Carneiro, M. S. de S., Pinto, A. P. Pompeu, R. C. F. F., Silva, D. S., Coutinho, M. J. F. \& Fontenele, R. M. (2015). Avaliação da composição químico bromatológica das silagens de forrageiras lenhosas do semiárido brasileiro. Semina: Ciências Agrárias, 36, $571-578$.

Souza, E. Y. B. Muniz, E. N. Santos Filho, P. F. dos, Rangel, J. H. de A., Galati, R. L., Santana Neto, J. A., Santos, D. de O. \& Castro Filho, E. S. (2012). Avaliação da qualidade nutricional da silagem de milho confeccionada com diferentes proporções de gliricídia. In: Anais do VII Congresso Nordestino de Produção Animal e XII Simpósio Nordestino de Alimentação de Ruminantes, p. 1-3. 